\title{
Reseña del libro: Una generación desconocida. Movimiento social demócrata cristiano, 1962-1970: \\ Testimonios
}

\author{
Book Review: Una generación desconocida. \\ Movimiento social demócrata cristiano, 1962-1970: \\ Testimonios
}

José Roberto Mendirichaga Dalzell *

\begin{abstract}
* Maestro en Letras Españolas por la UANL y Doctor en Historia po la UIA. Cultiva el ensayo y la biografía. Autor de la flama en el tiempo (UANL, 2016) y memoria del $\mathrm{H}$. Cuerpo Consular en Monterrey, c. 1840-2018 (UDEM, 2019). Ha enseñado, entre otros cursos de: Introducción a la Filosofía, Literatura Universal y Estudios Mexicanos. Actualmente enseña Literatura Mexicana e Historia de México. Colabora en las revistas anuarios Actas, Armas y Letras, Humanitas y The Journal of South Texas. Pertenece a SOMEHIDE y SNHGyE. Profesor emérito de la Universidad de Monterrey. Correo electrónico: jose.mendrichaga@udem.edu

(1) https://orcid.org/0000-0001-9102-8807
\end{abstract}

Historial editorial

Recibido: 24-mayo-2019

Aceptado: 01-abril-2019

Publicado: 23-septiembre-2019

ISSN-e: 2594-2956 


\section{Reseña del libro: Una generación desconocida. Movimiento social demócrata cristiano, 1962-1970. Testimonios}

Se trata de un libro interesante porque rescata del olvido un movimiento que influyó en muchos jóvenes de su tiempo para su posterior desenvolvimiento en la acción social.

Se dio en el marco del Concilio Vaticano II, la Guerra de Vietnam, el grito hippie de "Amor y paz", la Revolución Cubana, los niños de Biafra, los asesinatos de Robert Kennedy y Martin Luther King, y los movimientos estudiantiles de Japón, Estados Unidos, Francia y México.

Quienes escriben sus testimonios son: María Teresa Guerrero, Alfredo Gutiérrez, Ramiro Trevizo, Jesús Trevizo, Francisco José Paoli, Francisco José Camou, Miguel Bazdresch, Fernando Michel, Guadalupe de la Peña, Jesús Verver, Vicente Romero, Juan Antonio Irizar, José Ascención Viccon, Aurora Mora y Alberto Rascón, en ese tiempo residentes en las ciudades de México, Guadalajara y Chihuahua, fundamentalmente.

¿Por qué resulta ser importante este capítulo de la vida estudiantil, económica, social, política y religiosa de esta generación? Porque los nombres de algunos de sus integrantes marcaron una época en México y quienes viven continúan haciendo una destacada labor profesional y social en nuestro medio.

210 ¿Cuáles eran las fuentes doctrinales de los jóvenes de este tiempo? Los evangelios, las encíclicas sociales de los papas, los documentos del Vaticano II y los escritos o discursos de Louis Blanc, Carlos Marx, Jacques Maritain, Emmanuel Mounier, Antonio Gramsci, Iván Illich, 
José Carlos Mariátegui, Theilhard de Chardin, Graham Green, Ignace Lepp, Paulo Freire, Ernesto "Che" Guevara.

Algunos nombres de los integrantes del Movimiento Social Cristiano fueron: Manuel Rodríguez Lapuente, Hugo Gutiérrez Vega, Carlos Arriola, Carlos Núñez, Horacio Guajardo, Miguel Ángel Granados Chapa, Rafael Rodríguez Castañeda, Miguel José Yacamán, José Trueba, Fernando Baeza, entre otros.

Vayamos con lo medular que abordan cada uno de quienes dan testimonio del movimiento. En la introducción, María Teresa Guerrero explica cómo surgió la idea de intentar, a partir del Evangelio, una forma de planteamiento ante "la absurda post-modernidad y la globalización mercantil" (p. 15), sin pretender hacer una historia del Movimiento Social Demócrata Cristiano (MSDC). Para Alfredo Gutiérrez, la Democracia Cristiana (DC) en Chihuahua buscaba, entre los cincuentas y los sesentas, "abrir otros caminos en la vida política de México" (p. I7), donde se trabajaba por la acción autogestiva de las bases.

Ramiro Trevizo narra cómo los integrantes del MSDC en Chihuahua pretendieron que el Partido Acción Nacional (PAN) se alineara en la Democracia Cristiana Internacional, lo que no se logró. Jesús Trevizo documenta la experiencia de una de las acciones del MSDC: la creación del Instituto de Capacitación y Desarrollo Social para Trabajadores y Campesinos, que recibió financiamiento de la organización Misereor.

Francisco José Paoli da cuenta de cómo trabajaron los miembros del MSDC con la Juventud Obrera Católica (JOC), el Frente Auténtico del Trabajo (FAT) y el Secretariado Social Mexicano, distante de los "grupos ultraconservadores" (p. 6o) como Yunques, Tecos y miembros 
del Frente Universitario Anticomunista de Puebla. Viene luego un largo testimonio de Alfredo Gutiérrez que narra su acercamiento al Centro Cultural Universitario atendido por los padres dominicos, al Instituto Técnico de Estudios Sindicales y a simpatizantes o integrantes del MSDC como Horacio Guajardo, Miguel Ángel Granados, Vicente Leñero y Alejandro Avilés. "La derecha conservadora y reaccionaria era tan enemiga nuestra como la izquierda dogmática” (p. 137), señala Gutiérrez.

Recuerda Francisco José Camou al padre Porfirio Miranda, a Diego Fernández de Cevallos, a Fernando Baeza y a otros integrantes del MSDC. Camou cierra su testimonio con "La salida del 7o" (p. I56), que significó "la clausura del intento de hacer de la democracia cristiana una fuerza política del país" (p. 156). Enseguida aparece otro también largo testimonio que corresponde a María Teresa Guerrero, quien evoca su experiencia misionera en el Instituto Femenino de Chihuahua, la Acción Católica y la JOC; y el conocimiento del movimiento de Madera, las huelgas de Euzkadi, Pepsi Cola y Spicer, la UNAM, la UIA, Flacso, Ilades, el '68, el 2 de Octubre, don Sergio Méndez Arceo, y el regreso de algunos al PAN y la desbandada al PMT, al PRD o al ostracismo.

Para Miguel Bazdresch, no habría que olvidar los cursos de DC en el ITESO, el IMDEC, más lo realizado por la Congregación Mariana San Felipe y la vinculación con la Unión de Obreros Guadalupanos.

212 Fernando Michel da cuenta de su presencia en el Crefal. Guadalupe de la Peña evoca su venturosa estancia en Chihuahua, donde conoció a Hernán Villarreal Junco, Luis del Valle y Raúl H. Mora, entre otros, y pudo ver la apertura de una escuela de trabajo social. Y Jesús Verver escribe: "Creíamos que de verdad arrancábamos en México la tercera vía, no capitalista ni comunista, al menos ilusamente así lo creí” (p. 24I). 
Como textos finales están los de Vicente Romero (el ejemplo de Anacleto González Flores), José Antonio Irizar ("en el mundo bipolar de la época éramos anti-imperialistas y cristianos por el socialismo" (p. 260), José Ascensión Viccon (las Jornadas de Vida Cristiana, el Grupo BACE, la revista Crisis, el Cidoc), Aurora Mora (la Unión Femenina de Estudiantes Católicas, el asesor jesuita David Mayagoitia, la Teología de la Liberación, la negativa acción del MURO), y Alberto Rascón (el arzobispo Adalberto Almeyda, la Casa Javier, la Juventud Demócrata Cristiana). En el Colofón, María Teresa Guerrero se duele del fraude electoral del 2012 y, citando a Ramiro Trevizo, afirma que "sólo queda refundar la nación" (p. 328) .

\section{Referencias}

Guerrero Olivares, M.T. (Comp.). (20I4). Una generación desconocida. Movimiento social demócrata cristiano, 1962-1970. Testimonios. Chihuahua, México: Instituto Chihuahuense de la Cultura / Gobierno del Estado.

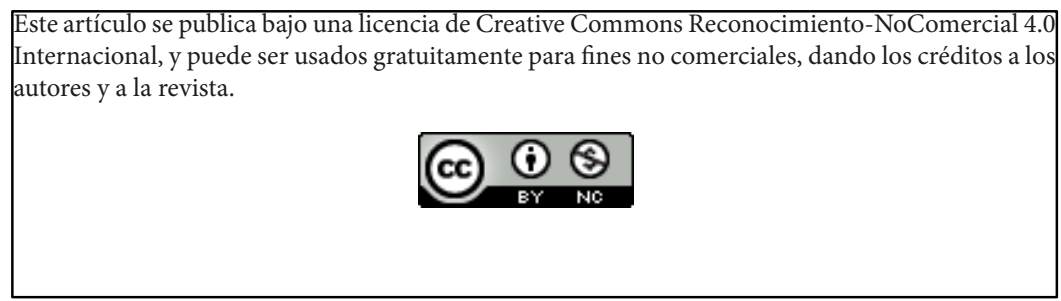

